\title{
Women's role in adapting to climate change and variability
}

\author{
Y. Carvajal-Escobar ${ }^{1}$, M. Quintero-Angel ${ }^{1}$, and M. García-Vargas ${ }^{2}$ \\ ${ }^{1}$ School of Natural Resources and Environmental Engineering, EIDENAR, Universidad del Valle, Cali, Colombia \\ ${ }^{2}$ Institute of Research and Development in Water Supply, Environmental Health and Conservation of Water Resources, \\ CINARA, Universidad del Valle, Cali, Colombia
}

Received: 14 June 2007 - Revised: 12 January 2008 - Accepted: 15 February 2008 - Published: 10 April 2008

\begin{abstract}
Given that women are engaged in more climaterelated change activities than what is recognized and valued in the community, this article highlights their important role in the adaptation and search for safer communities, which leads them to understand better the causes and consequences of changes in climatic conditions. It is concluded that women have important knowledge and skills for orienting the adaptation processes, a product of their roles in society (productive, reproductive and community); and the importance of gender equity in these processes is recognized. The relationship among climate change, climate variability and the accomplishment of the Millennium Development Goals is considered.
\end{abstract}

\section{Introduction}

Climate change $(\mathrm{CC})$ is a reality recognized as the greatest challenge for societies in the XXI century (Vincent, 2007). Although in recent years important advances have been made in reducing the losses in the face of the associated hazards, their impact continues being considerable (Thomalla et al., 2006), almost $90 \%$ of deaths in disasters today have a hydro meteorological origin (UNDP, 2004). Although adaptation is perceived as being very important to protect societies against the effects of climate variability $(\mathrm{CV})$ and $\mathrm{CC}$, the statistics reveal a disproportionate impact in developing countries and on less-favored populations (Burton et al., 2006).

Although the hazards associated with $\mathrm{CC}$ and $\mathrm{CV}$ impact societies all over the world, it is important to recognize that they have a different effect on men and women, ethnic groups, social classes, age groups, etc. Despite the importance of recognizing gender-related differences, both the United Nations Framework Convention on Climate Change

Correspondence to: Y. Carvajal-Escobar

(yecarvaj@univalle.edu.co) and the Kyoto Protocol fail on referring the issue (Pandey, 2005). However, women are more strongly affected by the effects of CC and CV (Lambrou and Piana, 2005); but the structures and the patriarchal ideology on which the development projects have been based have led to women's invisibility.

In the literature on gender and disasters, a call for adopting greater gender awareness is perceived in disaster prevention and attention, recognizing important advances in the understanding of the dimensions of gender. It is also stated that women are more vulnerable in disasters; that they have unique capacities as community leaders or managers of natural resources and that they are underutilized in strategies for managing emergencies (Cupples, 2007). Nonetheless, in the scientific literature on $\mathrm{CC}$, it is beginning to be suggested that women generally understand better the causes and local consequences of changes in the climatic conditions (Röhr, 2007) and have the knowledge and skills for orienting the adaptation process (O'Connor et al., 1998).

This descriptive research based in literature review and a critical analysis of authors, describes the impacts of CC and $\mathrm{CV}$ on one of the most vulnerable groups - women - and analyzes both, their role on adaptation and their contribution to risk reduction, calling for equity in these processes.

\section{Impact of climate change and variability on vulnera- ble women in developing countries}

The impacts associated to CC and CV vary from one country to another, from one region to another, and within the same community as product of the magnitude and frequency of hazards and of the existing vulnerability, which can have varying degrees within societies. Generally the poorest populations and marginal groups are impacted the most; nevertheless, there can be a differential effect on men and women as a consequence of their social roles, inequalities in the

Published by Copernicus Publications on behalf of the European Geosciences Union. 
access to and control of resources, and their low participation in decision-making. In many parts of the world, women constitute the population most vulnerable to $\mathrm{CC}$ and $\mathrm{CV}$, due to certain inequitable conditions and situations (vulnerability factors) that place them at risk (Enarson, 2000; Lambrou and Piana, 2005; Röhr, 2007). Empirical evidence shows that they suffer a greater impact in a disaster or emergency; and economic losses have a disproportionate effect on economically vulnerable women (Enarson, 2000). Changes in the workload suggest that disasters increase women's responsibilities in the domestic scene, in many paid and unpaid workplaces in the formal and informal sectors and in the community during the stages of preparation and mitigation (predisaster), as well as in the reconstruction stage (post-disaster) (Lambrou and Piana, 2005). In the post-disaster stage there may also be high levels of violence against women (Enarson, 2000); Men frequently emigrate in search for work, leaving a gross part of the processes of response and reconstruction in the women's hands (Rivero, 2004). Nonetheless, their work in disasters and in the adaptation processes to $\mathrm{CC}$ and $\mathrm{CV}$ is still highly invisible.

\section{Recognition of women's role towards adaptation}

Due to the dynamics and diversity of the risk associated with $\mathrm{CC}$ and $\mathrm{CV}$, it is recognized that only with local participation and management is it possible to have awareness, knowledge and incentives for risk reduction and control (Lavell et al., 2004). At this level, vulnerable women have played an outstanding role. Multiple authors report that women have been capable of mobilizing the community in the different phases of the risk-management cycle (Guha-Sapir, 1997; Enarson, 2001; Yonder et al., 2005), also in the adaptation context (see: Both ENDS, 2007). In the Latin American context, it is possible to highlight some experiences (Shrader and Delaney, 2000; GWA and WSP, 2005; UNDP, 2005) and other less studied cases such as in Ginebra, a municipality in, Valle del Cauca - Colombia (Carvajal and Quintero-Angel, 2007).

Generally, women seek solutions to the lack of drinking water, access to health and education, reducing factors of vulnerability of their communities in the face of hydrometeorological events associated with $\mathrm{CV}, \mathrm{CC}$ and other potential hazards, establishing networks with other women that increase their social capital. In their professional development or in their domestic activities, women are often in a better position to note certain environmental hazards. They are aware of the patterns of sicknesses in the children in the neighbourhood, and they can quickly detect changes in the water when they wash clothes or strange smells in the ground where their children play (Harding, 1998). At local levels, are the women who have greater clarity about what diverse social groups lose in the short term after a cyclone or an earthquake, who in the community are at risk and what is needed, and which native trees should be protected (Enarson and Fordham, 2001).
They develop a broad knowledge and experiences regarding their environment (Ariyabandu, 2004), which are being evaluated constantly and changed when the environmental and social conditions of their surroundings vary - product of the responsibilities that they assume within their families and in their communities. This knowledge is proving to be ever more valuable in developing countries (Harding, 1998) and should be taken into account in the adaptation of vulnerable communities to $\mathrm{CC}$ and $\mathrm{CV}$.

Even though it is true that in some spontaneous adaptations, there is limited knowledge of potential hazards or alternative adaptation strategies, in other cases adaptation is limited by other priorities like, scarcity of resources, and economic or institutional barriers (Bryant et al., 2000). Moreover, in many cases women's knowledge and skills are not taken into account in the planned processes, thereby affecting sustainability.

\section{Adaptation: a call for equity}

Considering that the lack of equity with respect to gender relations has limited the contribution of women to better manage hydrometeorological hazards in constructing processes of adaptation to $\mathrm{CC}$ and $\mathrm{CV}$, it is necessary to recognize the productive, reproductive and community roles that men and women play in the society; the practical and strategic genderrelated needs (which include the material needs from men and women to satisfy the basic needs of life - water, shelter, food, income and health care, and their relative status and power structures within the community, respectively. Strategic needs may include gaining legal rights, closing wage gaps, protection against domestic violence, among others, and its satisfaction requires structural and attitudinal changes in the community); the goods to which women and men have access; and the management of power and decision-making at all levels.

The multiple family, community and productive functions that women perform in society are sources of knowledge and abilities to take action in the processes of adaptation and risk reduction. At the same time, however, this can also make them more vulnerable if there is no equity between men and women with respect to the responsibilities that they should assume in those processes. Adaptation strategies led by women can benefit the household or the community, but can have a negative effect on them, becoming an obstacle for accomplishing the Millennium Development Goals (MDG), which recognize that the lack of equity between men and women has a negative effect on countries' development (UN/ISDR, 2003). Strategies of adaptation where women are overburdened with work in the domestic, labor and community circles are an example.

The foregoing demonstrates that, as in the case of natural disasters, the adaptation to $\mathrm{CC}$ and $\mathrm{CV}$ is closely related to the processes of human development. On the one hand, the 
materialization of the risk associated with $\mathrm{CC}$ and $\mathrm{CV}$ endangers development; while on the other hand, the developmentrelated decisions at all levels can generate new risks (UNDP, 2004). However, the inclusion of adaptation and risk management (RM) in the processes of planning for development can reduce existing risk factors and avoid social construction of new ones in societies.

Bearing in mind that $\mathrm{CC}$ introduces new dimensions to the social construction of risk, it is important to approach it with a holistic vision; taking advantage of and linking the adaptation to CC and CV, as well as to RM given that these are closely related processes that will make it possible to reduce the vulnerability and benefit from past experiences to face the new challenges that the accelerated change in the climate and world globalization create for the future.

\section{Conclusions}

$\mathrm{CC}$ and the increased potential risk of disasters are closely related; both are development issues that constrain the sustainability and the resilience of societies. CC, CV, and extreme environmental events leading to natural disasters clearly bear on development and have profound implications for accomplishing the MDG. Only to the extent to which it is understood that $\mathrm{CC}, \mathrm{CV}$, natural disasters, management of water and development are interconnected, will it be possible to structure more effective strategies to confront the problem.

As a product of their social roles, women perform a fundamental role in their communities in reducing the risk of disaster and searching for strategies of adaptation. Faced with the manifestations of $\mathrm{CV}$ and $\mathrm{CC}$, their knowledge and experience should be taken into account when planning adaptation processes for vulnerable communities. However, it is important to consider that in these processes men also intervene and could play decisive roles. Therefore, it is necessary to promote strategies for adaptation through inclusive and consultative processes that give participation to both men and women exposed to risks, taking into account the needs and expectations of both, and addressing a perspective of gender equity. In this sense, adaptation processes are an opportunity for questioning and changing traditional gender relations in society.

Given the limited data currently available on gender and $\mathrm{CC}$ and the invisibility that women's work still has in risk reduction and in the processes of adaptation, it is necessary to promote for more and better documentation of experiences (best or lost practices) in this field.
Acknowledgements. The authors are grateful to the Inter American Institute for Global Change Research (IAI) and the National Science Foundation (NSF) for financing this work, within the framework of the project "Useful Practices for Adaptation in Hydrometeorological Events Associated with Change and CV in Latin America and the Caribbean" and to the Research Group in Water Resources Engineering and Development of Soils (IREHISA), at Universidad del Valle, Cali, Colombia.

Edited by: P. Lagos

Reviewed by: E. Enerson and P. Aldunce

\section{References}

Ariyabandu, M.: Women, the risk managers in natural disasters, in: Gender Equality \& Disasters Risk Reduction Workshop, available at: http://www.ssri.hawaii.edu/research/GDWwebsite/pdf/ Ariyabandu.pdf, 8 pp., 2004.

Both ENDS.: Adapting to climate change: How local experiences can shape the debate, Briefing Paper, available at: http://www. bothends.org/, 17 pp., 2007.

Bryant, C. R., Smith, B., Brklacich, M., Johnston, T. R., Smithers, J., Chiotti, Q., and Singh, B.: Adaptation in Canadian agriculture to climatic variability and change, Clim. Change, 45, 181-201, 2000.

Burton, I., Diringer, E., and Smith, J.: Adaptation to climatic change, international policy options, The Pew Center on Global Climate Change, Arlington, USA, available at: http://www. pewclimate.org/docUploads/PEW_Adaptation.pdf, 36 pp., 2006.

Carvajal, Y. and Quintero-Angel, M. Que viva la montaña, Caso de Estudio Ginebra (Colombia), available at: http://climadapta. univalle.edu.co/casos.htm, 6 pp., 2007.

Cupples, J.: Gender and Hurricane Mitch: Reconstructing subjectivities after disaster, Disasters, 31, 155-175, 2007.

Enarson, E.: Gender issues in natural disasters, Talking points and research needs, in: Focus Programme on Crisis Response and Reconstruction Workshop, 48, ILO, Geneva, 30 pp., 2000.

Enarson, E.: What women do; gendered labor in the Red River Valley flood, Environ. Hazards, 3, 1-18, 2001.

Enarson, E. and Fordham, M.: From women's needs to women's rights in disasters, Global Environ. Change B, Environ. Hazards, 3, 133-136, 2001.

Guha-Sapir, D.: Women in the front line: Women in developing countries should be key players in disaster preparedness and relief, UNESCO Courier, Paris, 27-29, 1997.

GWA and WSP: Construyendo una visión para la acción: Avances y desafíos de la transversalización del enfoque de género en la gestión integrada de recursos hídricos en América Latina, available at: http://www.agualatina.net/pdf-LAC/Water_Sanitation and_Hygiene/Water_and_Sanitation/genero_GWA.pdf, 54 pp., 2005.

Harding, S.: Women, science, and society, Science, 281, 15991600, 1998.

Lambrou, Y. and Piana, G.: Gender: the missing component in the response to climate change, Food and Agriculture Organization of the United Nations, Rome, available at: http://www.fao.org/ sd/dim_pe1/docs/pe1_051001d1b.pdf, 46 pp., 2005.

Lavell, A., Mansilla, E., and Smith, D.: La gestión local del riesgo: Concepto y práctica, UNDP-CEPREDENAC, Managua, 2004. 
O'Connor, R. E., Bord, R. J., and Fisher A.: The curious impact of knowledge about climatic change on risk perceptions and willingness to sacrifice, Risk Decision and Policy, 3, 145-155, 1998.

Pandey, N.: Societal adaptation to abrupt climatic change and monsoon variability: Implications for sustainable livelihoods of rural communities, Report, Winrock International - India, New Delhi, available at: http://dlc.dlib.indiana.edu/archive/00001606/ 01/NPSocietal_Adaptation.pdf, 228 pp., 2005.

Rivero, R.: Género y desastres, in: El fenómeno El Niño en Perú y Bolivia. Experiencias de participación local, Memoria Encuentro Binacional Experiencias de Prevención de Desastres y Manejo de Emergencias ante el Fenómeno El Niño, Lima, Peru, 60-70, 2004.

Röhr, U.: Gender, climate change and adaptation. Introduction to the gender dimensions, available at: http://www.bothends.org/ service/casestudy_genanet.pdf, 11 pp., 2007.

Shrader, E. and Delaney, P.: Gender and post-disaster reconstruction: The case of Hurricane Mitch in Honduras and Nicaragua, The World Bank Report, 2000.
Thomalla, F., Downing, T., Spanger-Siegfried, E., Han, G., and Rockström1, J.: Reducing hazard vulnerability towards a common approach between disaster risk reduction and climate adaptation, Disasters, 30, 39-48, 2006.

UN/ISDR: Women, disaster reduction and sustainable development, WMO Bulletin, 52(2), 150-155, 2003.

UNDP: Reducing disaster risk, a challenge for development, a global report, United Nations Development Programme, New York, 2004.

UNDP: Guardianas de la ladera, una estrategia preventiva y de generación de ingresos a grupos vulnerables desde la Alcaldía de Manizales, Gestión local del riesgo y preparativos de desastres en la región andina, sistematización de buenas prácticas y lecciones aprendidas. United Nations Development Programme, Quito, 2005.

Vincent, K.: Uncertainty in adaptive capacity and the importance of scale, Global Environ. Change, 17, 12-24, 2007.

Yonder, A., Akcar, S., and Gopalan, P.: Women's participation in disaster relief and recovery, Seeds 22, Population Council, New York, 2005. 